\title{
Title: Assessing spatial patterns of soil erosion in a high-latitude rangeland
}

Short title: Erosion patterns in a high-latitude rangeland

Streeter $\mathrm{RT}^{1}$, Cutler $\mathrm{NA}^{2}$

1. School of Geography \& Sustainable Development, University of St Andrews, UK*

2. School of Geography, Politics \& Sociology, Newcastle University, UK

* Corresponding author, Richard Streeter, rts3@st-andrews.ac.uk

\begin{abstract}
High-latitude areas are experiencing rapid change: we therefore need a better understanding of the processes controlling soil erosion in these environments. We used a spatiotemporal approach to investigate soil erosion in Svalbarðstunga, Iceland $\left(66^{\circ} \mathrm{N}, 15^{\circ}\right.$ $\mathrm{W})$, a degraded rangeland. We used three complementary datasets: 1 ) high-resolution UAV imagery collected from 12 sites (total area $\sim 0.75 \mathrm{~km}^{2}$ ); 2) historical imagery of the same sites; and 3) a simple, spatially-explicit cellular automata model. Sites were located along a gradient of increasing altitude and distance from the sea, and varied in erosion severity (5$47 \%$ eroded). We found that there was no simple relationship between location along the environmental gradient and the spatial characteristics of erosion. Patch-size frequency distributions lacked a characteristic scale of variation, but followed a power-law distribution on five of the 12 sites. Present total eroded area is poorly related to current, site-scale levels of environmental stress, but the number of small erosion patches did reflect site-level stress. Small $\left(<25 \mathrm{~m}^{2}\right)$ erosion patches clustered near large patches. The model results suggested that the large-scale patterns observed likely arise from strong, local interactions, which mean that erosion spreads from degraded areas. Our findings suggest that contemporary erosion patterns reflect historical stresses, as well as current environmental conditions. The importance of abiotic processes to the growth of large erosion patches and their relative insensitivity to current environmental conditions makes it likely that the total eroded area will continue to increase, despite a warming climate and reducing levels of grazing pressure.
\end{abstract}

Keywords:

UAV - grazing - patch-size distributions - soil erosion - Iceland - sheep - cellular automata

This article has been accepted for publication and undergone full peer review but has not been through the copyediting, typesetting, pagination and proofreading process which may lead to differences between this version and the Version of Record. Please cite this article as doi: 10.1002/ldr.3585 
Main text

\section{Introduction}

Soil erosion is a global phenomenon that results in the long-term loss of ecosystem services (Lal, 2014). Climate change and anthropogenic pressures, notably over-grazing, are two key stressors, and the impact of these factors on erosion has been extensively studied in lowand mid-latitude locations. However, high-latitude regions are also susceptible to soil erosion (Grosse et al., 2011; Hilton et al., 2015; Heindel et al., 2015). It is therefore vital to understand the processes behind soil erosion in these environments in order to mitigate against future soil degradation and loss.

High-latitude environments are disproportionately affected by climate change: mean temperatures in these regions increased by about $1^{\circ} \mathrm{C}$ per decade in the period $1980-2010$ (significantly above the global increase), and precipitation regimes (especially the depth and duration of snow cover) are also changing (IPCC, 2013). Climate change exacerbates soil erosion (Amundson et al., 2015) and can also lead to enhanced anthropogenic stress, as previously marginal habitats become viable for agriculture and human habitation (IPCC, 2014). In contrast to the trend in mid- to low-latitudes, it is possible that climate change will lead to a reduction in stress in high-latitude areas, and a slowing/reversal of current erosion (e.g. Tape et al., 2011). However, the precise impacts of global change on high-latitude soil erosion are poorly understood. Thus, the overall aim of this study is to understand the interaction of geomorphological and biological processes driving soil erosion in a highlatitude environment, through an analysis of landscape-scale spatial patterns.

The study of spatial patterns in ecosystems, and vegetation cover in particular, has a long history (see, e.g., Watt, 1947). This research is motivated by the desire to uncover the underlying processes that drive spatial patterning. Exogenous controls on the spatial patterning of vegetation at a landscape scale (e.g., variation in slope, aspect, geology, etc.) are well understood (Fortin \& Dale, 2005). However, endogenous biological processes can also lead to the emergence of patterned vegetation cover, even where exogenous controls are spatially homogeneous ('self-organised patchiness': Rietkirk et al., 2004). Landscapescale studies of spatial pattern need to acknowledge both endogenous and exogenous factors, as well as their interaction via biophysical feedbacks.

Spatial patterns in the landscape have been used as an indicator of the underlying resilience of an ecosystem, and - contentiously - an early warning signal of abrupt transitions between alternative stable states (e.g., the transition from a vegetated to eroded landscape: Kéfi et al., 2007). Previous studies have used an array of different spatial metrics to assess proximity to abrupt ecological transitions, although experimental studies (in particular those from high-latitude habitats) are rare (Kéfi et al., 2014; Scheffer et al., 2001). 
An influential study by Kéfi et al. (2007) found that vegetation patch sizes followed a powerlaw distribution under low stress (grazing pressure) conditions. They attributed this to strong, positive biological interactions (facilitation) operating over short distance scales. Under increased grazing pressure, facilitative interactions broke down, the proportion of large vegetation patches decreased, and the patch size distribution diverged from a powerlaw relationship. Kéfi et al. (2007) therefore proposed that patch size distribution could be used as an early warning signal for abrupt transitions. Their findings have been the source of debate (see, e.g., Meloni et al., 2017) and the precise mechanisms underlying power-law distributions in patch sizes remain obscure. However, whatever the underlying processes, there is evidence that the spatial configuration of vegetated and unvegetated terrain has the potential to reveal information about the key biophysical processes. We applied this approach in this study of soil erosion in northeastern Iceland.

Large parts of Iceland are characterised by landscape-scale patchworks of eroded and noneroded areas (Figure 1b). We have a good understanding of the long-term, large-scale progression of soil erosion in Iceland, which has been driven by a combination of climatic deterioration, volcanic activity and over-grazing (Arnalds, 2005; Streeter et al., 2015). Iceland's andosols are friable, free-draining and easily eroded; once vegetation cover is removed the underlying sediment is vulnerable to erosion, and is often completely removed, exposing the underlying bedrock or glacial lag deposits. The substrates created by soil erosion are extremely difficult for plants to colonise, and, once initiated, erosion patches may persist with minimal vegetation cover for centuries (Arnalds, 2005). This suggests the existence of biophysical feedbacks that create hysteresis in the system.

Whilst the large-scale factors that drive soil erosion in Iceland are well known, we still don't fully understand how the landscape-scale pattern emerges. Qualitative models of erosion patch initiation and growth have been proposed. For example, Ólafsdóttir \& Guðmundsson (2002) presented a conceptual model where random breaks in vegetation cover become erosion patches, which expand due to geomorphological processes (notably cryoturbation and aeolian action). The distinctive spatial pattern of the eroded areas (Figure 1b) emerges as erosion fronts propagate and patches merge (Dugmore et al., 2009). However, these models remain largely untested, and this limits our ability to predict the impact of future environmental change. Recent climatic amelioration and reductions in grazing intensity might be expected to reduce the rate and intensity of erosion. However, it has proved difficult to stop/reverse erosion, even when grazing is completely excluded (Barrio et al., 2018). To better understand why erosion has continued and to predict the response of these landscapes to future environmental change quantitative models of erosion patch initiation and growth are required.

We conducted a spatiotemporal study of erosion patches on a site in northeastern Iceland. As our primary concern was the progression of erosion, we inverted the normal approach of 
surveying vegetation patches, and focussed on the spatial structure of areas where vegetation was absent (i.e., erosion patches). Based on previous studies, we postulated that:

1) The erosion patches were the result of biophysical interactions, i.e., biological processes (plant growth, regeneration and colonisation) that maintain soil cover and geomorphological processes (erosion by wind and water) that promote soil loss. The relative balance of these factors would determine the initiation and development of the patches and, by extension, their spatial characteristics.

2) As environmental stress increases, biological processes become less influential, and geomorphological processes more influential.

3) Soil erosion is initiated by random, small-scale disturbances that rupture the vegetation cover. Incipient erosion patches either grow, or 'heal' (become revegetated), according to prevailing environmental conditions.

4) Environmental stress in vegetated areas increases with proximity to existing erosion patches (due to exposure to drought stress, wind, etc.), although this is likely to be a short-range effect (a few metres, at most).

To study the impact of environmental stress on the spatial patterning of the erosion patches, we selected sites arranged along a gradient of climatic stress (expressed in terms of altitude/distance from sea).

We hypothesised that:

$\mathrm{H} 1$ : The number and proportional coverage of erosion patches would increase with altitude/distance from the sea as climatic conditions became more stressful.

$\mathrm{H} 2$ : The patch size distribution would vary with altitude/distance from the sea. On low/proximal sites, climatic stress would be lower, erosion patches would 'heal' more readily and large patches would be under-represented (a truncated power-law distribution). On high/distal sites, the increasing stress would lead to patch growth and coalescence, resulting in an over-representation of large patches.

H3: Erosion patches would be clustered in space as a) the initiation of new patches is more likely near existing patches and $b$ ) new patches that form near existing ones are less likely to become revegetated. Therefore, even though the notional start of erosion may be spatially random, feedbacks eventually lead to a clustering of erosion features.

\section{Materials and Methods}

To address the spatiotemporal nature of soil erosion, and the potential impacts of changing ecological stress in the future, our analysis combined three distinct datasets. First, we analysed the current spatial structure of the extant erosion patches, using high-resolution remote sensing data. Secondly, we compared our findings to historical imagery. Finally, to 
illuminate the long-term development of an eroded landscape and the effect of increasing stress, we also formulated a simple spatial model of patch initiation, growth and persistence.

\subsection{Study area}

This work was undertaken in 12 study sides (labelled A-L in Figure 1a) located in an area known as Svalbarđstunga, northeastern Iceland. As far as possible we selected sites which had low relative relief, homogenous vegetation cover, and a similar hydrology. The 12 sites surveyed were arranged along a north-south transect and ranged in elevation from $11 \mathrm{~m}$ to $223 \mathrm{~m}$ asl, and from $0.2 \mathrm{~km}$ to $14.3 \mathrm{~km}$ from the coast (Table 1). The total proportion of eroded area ranged from $5-47 \%$ and the median area eroded was $25 \%$.

The nearest climate station is on the coast at Raufarhöfn, located $28-38 \mathrm{~km}$ to the northwest of the study sites. During 1949-2008 the mean annual temperature was $2.5^{\circ} \mathrm{C}$ and the mean annual precipitation $680 \mathrm{~mm}$ (Veðurstofa Íslands, 2019). The trend in recent times (1980-2008) has been for increasing mean annual temperature, from around $2{ }^{\circ} \mathrm{C}$ in the early $1980 \mathrm{~s}$ to $3^{\circ} \mathrm{C}$ by the mid-2000s. There is an expected environmental gradient (i.e. increasing global-scale stress) between the sites, due to the generally increasing altitude and distance from the sea from north to south along the transect. Additional climate variables such as snow cover and wind exposure, and their interaction with grazing, will vary between sites. However, the overall pattern of increased levels of stress at higher altitude and greater distance from the sea sites is likely to remain the same. Further details on the climate gradient are provided in the supplementary text.

All the sites were located within unfenced rangeland areas, shared by local farms. During the grazing season (typically May-September) sheep move freely across these rangelands. Nationally sheep numbers in Iceland have declined since a peak in the late 1970s, and by the mid 1990s the numbers were about half what they were in 1980. From the mid-1990s numbers have been relatively stable (Marteinsdóttir et al., 2017). At the farm Svalbard (Figure 1a) sheep numbers have been more-or-less constant for the period 1980-present.

The vegetation on the study sites was dominated by low-growing shrubs, notably bog bilberry (Vaccinium uliginosum), crowberry (Empetrum nigrum) and dwarf willow (Salix herbacea). Patches of dwarf birch (Betula nana) up to about $60 \mathrm{~cm}$ high were present at some of the sites. Soils in the area are classified as a patchwork of brown andosols, which dominate nearer the coast, and histosols, which tend to be found more frequently inland (Arnalds, 2015). Both soil types are derived from mainly volcanic material and are sensitive to disturbance. Further details on the vegetation cover, soils and past land use is in the supplementary text. 
Even though there are no areas of permafrost within the study area, the high water retention properties of the soil, coupled with intense freeze-thaw cycles, mean that cryoturbation is common. In vegetated areas this cryoturbation is expressed through the occurrence of earth-hummocks (Icelandic: thúfur) - low, dome-shaped, elliptical mounds separated by a network of depressions, elongating into mounded stripes where the slope was steeper (Figure 1c). Thúfur were abundant at all the study sites.

\subsection{UAV image survey}

The typical spread of individual plants on our sites (and therefore the likely size of the smallest erosion patches) is $10-60 \mathrm{~cm}$ (Kristinsson, 2010), so images with a pixel size of $>50$ $\mathrm{cm}$ cannot capture the smallest erosion patches. To ensure that we captured the smallest likely scale of patterning we used unmanned-aerial vehicles (UAVs) to take images in the study area. During August 2017 we used two UAVs to collect high resolution images ( 2 $\mathrm{cm} /$ pixel) at the 12 sites. Details of the UAVs and the flight conditions are shown in Table S1. Flight plans were programmed using Map Pilot (v 3.1.4) software, which ensured that adjacent images had a $75 \%$ overlap. Each site was surveyed within a period of 20 mins so that light conditions were consistent. At each site we took one set of images in RGB and one set of images with a modified RGB camera which used a filter to capture RG and a nearinfrared (NIR) band. The RG-NIR images allowed us to calculate a relative normalised difference vegetation index (NDVI) map for each site using the NDVI formula (e.g. Pettorelli et al., 2005). Although using a modified RG-NIR camera is not a substitute for using a full multi-spectral sensor to make NDVI measurements (especially in situations where absolute measurements are required, e.g., to observe changes over a growing season), initial tests indicated the modified camera was capable of reliably distinguishing between areas with growing vegetation and those with no vegetation cover. Capturing both RGB and RG-NIR images allowed cross checking of the classification based on RG-NIR images.

Individual images were merged together to create an orthomosaic. An area of $250 \times 250 \mathrm{~m}$ $\left(0.0625 \mathrm{~km}^{2}\right)$ was then extracted for each study site. We only had enough suitable images at site A to extract an area of $240 \times 240 \mathrm{~m}$. Each orthomosaic was then downscaled to $5 \mathrm{~cm}$ pixel resolution using bicubic interpolation. Elevation data were generated by clipping a $2 \mathrm{~m}$ resolution DEM (the ArcticDEM, v3.0, Porter et al., 2018) to the site boundaries.

\section{Image classification and patch identification}

We used ImageJ (v.2.0) to manipulate the UAV data. We used the R and NIR bands from the RG-NIR images to calculate an NDVI value for each pixel on each site. We then used the NDVI values to classify the land surface into vegetated and unvegetated areas. We used the RGB images and ground truthing to determine an individual NDVI threshold for each site. This was done by manually selecting a minimum of 14 pixels in each cover category at each 
site and using this information to determine the best threshold value of NDVI to distinguish vegetated and non-vegetated pixels. In one instance, comparison with the corresponding RGB image found that this approach had failed to separate between true unvegetated areas and large patches of lichen cover. This site was excluded from the analysis. To test the accuracy of our classification we randomly sampled 100 pixels at each site and cross checked the pixel classification against a manual classification based on the corresponding RGB image. Globally the accuracy of pixel classification was $94 \%$. After pixel classification individual erosion patches were identified and labelled using an implementation of 1-pass connected components labelling in R (function ConnCompLabel from the SDMTools Package v 1.1).

\section{Statistical analysis of patch-size distribution}

The patch size distributions were estimated using cumulative probability distribution function (CDF). This describes the probability that an erosion patch has a size $\left(a \mathrm{~m}^{2}\right)$ equal to or greater than a determined area, $P$ (Patch $\geq a$ ). CDF was selected over other approaches such as probability density function, as it has been shown to be more sensitive to capturing changes in pattern fragmentation (Moreno-de las Heras et al., 2011). We did not bin values, as this has been shown to affect the conclusions drawn from the data (Meloni et al., 2017).

We compared two different models which described the empirical distribution of the patch sizes: 1) a power-law (PL) and 2) log-normal (LN) distribution. These were fitted to the CDF data using the R Package poweRlaw ( $v 0.7$ ), based on the principles outlined in Clauset et al. (2009). To determine if the PL model was a good description of the data we used a goodness-of-fit test with a boot-strapping (100 iterations) (Clauset et al., 2009). To compare the PL model with the LN model we used Vuong's test, which calculates a likelihood ratio as well as calculates a $p$-value for the figure (Clauset et al., 2009).

\section{?.5 Analysis of erosion patch location}

We investigated the spatial structure of the erosion patch centroids by a) calculating site level indices of dispersion (also known as variance-mean ratios) and b) conducting pointpattern analysis (Ripley's $L$-function). The index of dispersion, $I D$, is a simple, global statistic that expresses the ratio of the variance to the mean (Dale, 1999). If the erosion patch centroids are randomly distributed, the observations follow a Poisson distribution; in this case, the mean is equal to the variance and ID approximates unity. If the patches have a clumped (aggregated) distribution, the variance is high, and $I D$ is $>1$. We calculated $I D$ by dividing each site into a grid of $62510 \mathrm{~m} \times 10 \mathrm{~m}$ cells, enumerating the number of patch centroids in each cell, and calculating the mean and variance of these counts. 
We used point-pattern analysis of the erosion patch centroids to investigate structure at different spatial scales. To do this, we calculated Ripley's $L$-function for each site, using the spatstat package running in R (Baddeley et al., 2015). Briefly, the $L$-function compares the expected and observed number of erosion patches at different spatial scales (in this case, 0 $50 \mathrm{~m}$ ). Distributions exhibiting complete spatial randomness (CSR) produce $L$-function values to zero. Over-dispersed (segregated) distributions produce negative values and under-dispersed (aggregated) distributions positive values. The significance of the $L$ function was calculated using Monte Carlo techniques, using 99 iterations on random data of the same density (Haase, 1995; Fortin and Dale, 2005).

To understand if the location of small patches was affected by proximity to the edge of large patches, we conducted the following analysis. We defined large patches as those over 25 $\mathrm{m}^{2}$. This size was selected based on field observations that erosion patches of this size and larger were likely to have no remaining sediment cover over at least part of the patch area and therefore were likely to persist. This dataset allowed us to calculate the distance from the centroid of each small $\left(<25 \mathrm{~m}^{2}\right)$ erosion patch to the nearest edge of a large erosion patch. The distance from the edge of a large erosion patch to the centroid of a small erosion patch was then calculated for each patch at each site, and the median distance calculated for each site. We then performed a bootstrap analysis on the actual distances of patch centroids from patch edge 1000 times, in order to calculate the standard error of the median distance estimate. In addition, we generated a null dataset for each site in the following way. At each site, for areas outside large erosion patches, the distance of all pixel outside of a large erosion patch to the edge of the nearest large patch was calculated using the Proximity function in QGIS (v3.4). From this null dataset we sampled the same number of pixels as there were small erosion patches at each site. To determine the robustness of the null median distance estimate we sampled each site 1000 times, and then calculated the median distance for each iteration and the standard error for the whole dataset.

\subsection{Aerial photo analysis}

To understand long term changes at our sites we used greyscale aerial photographs of Svalbarðstunga. Images cover the study area from flights in July 1980 and August 1991 (Table S2). The image resolution was $\sim 0.56 \mathrm{~m} /$ pixel for the 1991 images and $\sim 0.73 \mathrm{~m} / \mathrm{pixel}$ for the 1980 images. We cropped the photographs to the site boundaries. In the aerial photographs eroded areas appear lighter in tone and vegetated areas darker (Figure S1). After cropping, images were resized to $333 \times 333$ pixels (a resolution of $0.75 \mathrm{~m} /$ pixel) and thresholded using ImageJ (Schindelin et al., 2012). This process was effective at capturing larger eroded areas, but could not resolve the numerous, small eroded areas we observed in the UAV imagery, and was sensitive to variations in the lighting and level of contrast within each image. The total non-vegetated (we assume eroded) area for each site was calculated from the thresholded image. Due to the inability of this method to pick up smaller eroded 
areas the total eroded area calculated from the aerial photographs is likely to be an underestimate of the true figure. After classification, the eroded area from 1980 and 1991 was compared to the eroded area in the 2017 UAV survey.

\subsection{Erosion modelling}

In order to a) see if we could replicate the spatial characteristics of the eroded landscapes, using a small number of parameters and $b$ ) to assess the impact of changing ecological stress on soil erosion, we created a simple cellular automata model of erosion in NetLogo ( $v$ 6.1.0; Wilensky, 1999). Further details on the model can be found in the supplementary text. The model had one type of entity: square cells arranged in a $200 \times 200$ grid. Each cell had one state variable: its land cover status. Land cover could be either vegetated or eroded.

The initial state of the model was entirely vegetated, as it is assumed that most lowland landscapes in Iceland were fully vegetated before settlement. At each time step the probability $\left(P_{e}\right)$ of a vegetated cell changing to an eroded state is calculated. The probability is a combination of the global-scale erosion probability $P_{e g}$, which is the same for all cells regardless of location, and the local-scale erosion probability $P_{e l}$, which varies depending on the status of the eight cells adjacent to that cell (Moore neighbourhood). Based on our knowledge of how erosion proceeds in Iceland, we assumed that once more than half of adjacent cells had become eroded, erosion in the target cell becomes likely.

The probability of revegetation $\left(P_{v}\right)$ is a combination of the global-scale probability $P_{v g}$, which is the same for all cells regardless of location, and the local-scale probability $P_{v l}$, which varies depending on the status of the eight cells adjacent to the target cell (Moore neighbourhood). Both the literature on Icelandic soil erosion and our own observations suggest that recolonization of bare sediment is difficult (Arnalds, 2015). The presence of adjacent vegetated areas increases the chances of success by providing seed sources, lateral regrowth, and through plant facilitation effects (Bertness and Callaway, 1994; Callaway et al., 2002), but we suspect that likelihood of revegetation is lower than that of erosion. This is reflected in our default parameter values (Table S3).

We tested if we could replicate our empirical observations using simple model parameters. We did this by conducting model runs until the proportion of eroded terrain reached $0.05-$ 0.55 under the following scenarios: a null model, with no spatial interactions, and the model described above. We then compared the model outputs against empirical datasets. We assessed 1) the range of patch sizes generated by the model at each overall level of eroded area and 2) if model runs created outputs with patch-size distributions which could be described by a PL model, where the scaling-exponent $\beta \leq 2$ and the $p$-value from a bootstrapping implementation of a goodness-of-fit test $\geq 0.05$. We also used the model to 
establish how the total eroded area changed through time. We did this by simulating the progression of erosion from fully vegetated to 0.95 proportion eroded 15 times, using the parameters stipulated in Table S3.

To assess the model sensitivity to transient periods of increased global (site-level) stress we simulated two scenarios. The first scenario had a constant low level of global-scale stress $\left(P_{e g}=0.002\right)$ and 3000 time-steps. The second scenario had a variable level of global-scale stress: $P_{e g}$ was 0.002 for time-steps 0-200, increased to 0.004 for time-steps 201-500, and decreased to 0.002 for time-steps 501-3000. Both scenarios were replicated 20 times.

\section{Results}

\subsection{Remote sensing of erosion patches}

The results of the land surface classification are presented in Figure 2. The number of erosion patches identified at each site was between 8206 and 50268. The total number of patches at each site was positively correlated with distance from the sea $\left(R^{2}=0.43, p=0.01\right.$, Figure $3 b)$ but not increasing altitude $\left(R^{2}=0.21, p=0.07\right.$, Figure $\left.3 a\right)$.

There was no correlation between the total eroded area at each site and increasing distance from the coast $\left(R^{2}=-0.01, p=0.36\right)$ or altitude $\left(R^{2}=-0.06, p=0.57\right)$ (Figure $\left.3, c-d\right)$. The total number of patches identified at each site and the total area eroded were uncorrelated (Figure S2).

\subsection{Erosion patch sizes}

The size of eroded patches found at the sites varied greatly, from $0.0025-20,732 \mathrm{~m}^{2}$, with the largest individual patch found at the most eroded site (site D). The largest individual patch accounted for $33 \%$ of its total site area. All sites exhibited a wide range of patch sizes, although there was a notable difference between individual sites, with the smallest range found at site $A$ (five orders of magnitude) and the largest at site $D$ (seven orders of magnitude).

The patch-size CDF (Figure 4) showed some variation between sites. Sites A and B displayed CDF distributions which declined relatively slowly up to $1 \mathrm{~m}^{2}$, before declining more steeply. Other sites had a fairly even CDF decline up to patch-sizes of $10-50 \mathrm{~m}^{2}$. Above this patch-size range the CDF declined more slowly and became more variable. The PL scaling exponent $\beta$ ranged from 1.78 to 2.27 , with 7 out of the 12 sites having a scaling-value $\beta<2$ for a powerlaw model fitted for the values above $x_{\min }$ (Table 2). The patch-size distributions from five 
sites ( $A, B, D, H$ and $I$ ) had a p-value $>0.05$, consistent with a PL distribution. When the PL models were compared with a LN model using Vuong's test, all sites had a p-value $>0.05$, i.e., a log-normal model could not be ruled out. The PL and LN models were both generally poor at capturing the largest patches observed at all the sites, however, in most cases the LN model appeared worse at capturing the large patches than the PL model (Figure 4).

The $P L$ scaling-value of $\beta$, and the $p$-value for the $P L$, had no relationship to the level of erosion observed - both the least eroded site $(A)$ and the most eroded site (D) could be described by a power-law relationship. Neither the value of the scaling-exponent, nor the PL p-value varied predictably with location along our environmental gradient.

Large patches were extremely important at determining the overall area of erosion at each site. On average, large patches $\left(>25 \mathrm{~m}^{2}\right)$ made up $86 \%$ of the eroded area across all sites. The number of large patches at each site ranged between 10-30. As the eroded proportion of each site increased, the contribution of large patches to the overall area eroded increased from less than $50 \%$ to over $97 \%$ (Figure 5 ).

\section{Location of erosion patches}

Erosion patch centroids were more highly aggregated in space than we would expect from random distributions. Indices of dispersion for the sites ranged between 12-86, indicating high levels of aggregation (Table S4). Calculation of Ripley's $L$-function demonstrated the significant aggregation of patch centroids applied across all spatial scales analysed (0-50 m: refer to Figure S3 for a typical figure). Small erosion patches tended to be close to the edge of large erosion patches: for 11 of the 12 sites, the median distance between small patch centroids and large patch boundary was less than anticipated value under the null model (Figure 6). Across all the sites, on average, half of all small erosion patches occurred within $3.5 \mathrm{~m}$ of the edge of a large erosion patch, whereas the median distance for any pixel from the edge of a large erosion patch was $7.9 \mathrm{~m}$.

\section{Aerial photo analysis}

The majority of large erosion patches observed in 2017 were already present in 1980 and 1991, and had a similar shape in 1980 as in 2017 (Figure S1). Over the period 1980-1991, seven sites exhibited a small (1-5\%) increase in the total area eroded, two sites showed no change, and three sites underwent a small decline (2-4\%). In 2017, 10 of the 12 sites had experienced increases in the area eroded of between 2-13\%, compared to 1980 (Figure 7). 


\subsection{Model scenarios}

Our model outputs were better than the null model at replicating the formation of large patches, even at relatively low proportions of the total area eroded.

For $43 \%$ of model simulations the CDF had PL like distributions (where $\beta<2$ and $p>0.05$ ), particularly at 0.15 eroded and above (e.g., Figure 8 , Table 3 ). This contrasts with the null model simulations, where fewer (19\%) of the models runs had PL like distributions, all these occurring at $\geq 0.35$ area eroded, and the range of patch sizes was low at sites where $<0.45$ area was eroded (Table 3 ).

Simulating the transition from a fully vegetated landscape to a 95\% eroded landscape with constant model parameters showed that the rate of erosion varied. Initially (i.e., between $0.05-0.15$ eroded) the rate of increase in the eroded area was rather slow. The rate increased once the eroded area reached 0.15 , and remained steady from 0.15 to 0.9 eroded, slowing just before the end of the simulation (Figure 9a).

We also used the model to explore the long-term impact of short periods of high globalscale stress on landscape development. Short periods of increased global-scale stress had a long-term impact on the progression of erosion. When global-scale level stress is below 0.003 the total eroded area remained below 0.1, regardless of scenario length (Figure 9b, Figure S4). When there was a period of high global-scale stress the eroded area increased rapidly (Figure 9b). However, after global-level stress returned to levels which previously had resulted in no increase in eroded area through time, the total eroded area continued to increase steadily (Figure 9b).

\section{Discussion}

This is, to our knowledge, the first high-resolution, quantitative spatial analysis of erosion patterning in Iceland. We were interested in what governs the patterning of erosion, and how erosion might progress in the future. Previous studies of landscape patterns have focussed on vegetation patches as their unit of interest (e.g., Moreno-de las Heras et al., 2011). These studies have frequently been in dryland regions, where vegetation patches occur within a matrix of exposed soil. This is not typically the case for our sites (or Iceland more generally). We know from past studies and palaeoenvironmental evidence that the patterns in Icelandic vegetation cover arise through the propagation of one uniform state (eroded) into an existing uniform state (vegetated), a progression that has been characterised qualitatively (Arnalds, 2015). Our sites span 53-95\% vegetation cover, so 
might be more usefully characterised as eroded patches within an intervening remnant vegetation cover.

Our results show that the spatial distribution of erosion patches is highly structured and that the patch-size distribution suggests scale-invariance, although for most sites we cannot say conclusively that they follow a power-law distribution. This evidence, alongside model results, implies that the patterns are a result of endogenous, short-range feedbacks, and that exogenous factors (such as global-scale site stress) are relatively unimportant in governing erosion patterns. However, exogenous factors probably do control the rate of erosion progression and erosion patch initiation.

\section{Erosion cover and global-scale environmental stress}

We hypothesised that at inland/higher altitude sites both the proportion of eroded area and number of erosion patches would increase (hypothesis H1). Contrary to our expectation, we found the proportion of eroded area did not vary predictably along the environmental gradient. It is likely this discrepancy is because the overall level of eroded terrain is strongly determined by large erosion patches, and that these patches are not in equilibrium with contemporary conditions.

It is possible that large erosion patches, which dominate the total area of erosion at each site, were initiated decades or centuries ago. Analysis of aerial photographs that predate our UAV survey by 37 years suggested that large erosion patches are long-lasting and relatively static features of the landscape. Geomorphological evidence from the south of Iceland suggests that large erosion patches may persist for centuries (Dugmore and Erskine, 1994). We know that, whilst some erosion occurred before the settlement of Iceland, it increased rapidly after humans arrived 1,100 years ago and was probably at its peak in the early $20^{\text {th }}$ century (Streeter et al., 2015). National sheep numbers (and therefore grazing stress) were also higher for about half of the time during the period 1850-1977 than at present (Arnalds and Barkarson, 2003) - likely leading to high rates of patch formation. In which case, there may be a legacy effect, i.e., the proportion of eroded terrain reflects the time since the establishment of large erosion patches. Additionally, rather than reflecting contemporary levels of environmental stress, the total area eroded could reflect historic differences in stress along our transect. For instance, grazing pressure could have varied markedly between sites in the past if they were subject to different land management regimes.

The number of erosion patches increased along the environmental gradient (i.e., patch number increased with global-scale stress). Contrary to our expectations, the number of 
patches did not decline with increasing area eroded (decreasing the area in which small patches could be found) (Figure S2). This is probably because highly eroded sites had more large erosion patches, each with a large 'apron' of small erosion patches around their perimeter. This effect probably compensated for the declining available area for small patches to be located on the more eroded sites. Most patches were small, and likely to be more dynamic than their larger counterparts (i.e., they are able to form and 'heal' much more rapidly). Patch number is therefore more likely to reflect current conditions than total eroded area. Whilst small patches are relatively unimportant in terms of total eroded area, they contribute towards the active growth of large erosion patches (by coalescence) and have the potential to become large patches themselves. We note that patch totals were skewed towards the smallest patches, and these were the patches likely to have the largest uncertainty in the remote sensing process. Additional work is needed to determine how quickly small erosion patches respond to changing environmental stress. Nevertheless, the number of small erosion patches $\left(<1 \mathrm{~m}^{2}\right)$ was relatively easy to determine using UAVs, and could be a useful indicator of site-level stress.

\section{Patch-size distributions}

One of our aims was to establish which category of patterning best described erosion on our sites, and to see if the pattern varied along our environmental gradient (hypothesis $\mathrm{H} 2$ ). Previous studies have identified two main categories of vegetation pattern, with contrasting patch size distributions. Firstly, regular or periodic patterns (Rietkerk and van de Koppel, 2008), and secondly scale invariant patterns, which lack a characteristic scale (Scanlon et al., 2007; Kéfi et al., 2007). In the past, the two patterns were thought to arise from the operation of qualitatively different processes. Regular vegetation patterns were generally attributed to the operation of endogenous, scale-dependent feedbacks (SDF) that resulted in self-organisation and the emergence of large-scale patterns from small-scale processes (e.g., facilitation or resource concentration). Scale-invariant patterns in landscapes may occur for a variety of reasons. Most simply, on any 2D grid very large patches could occur by chance - without any spatial interactions - when the total area eroded is near the percolation threshold of 0.59 (Stauffer et. al, 1994). Scale-invariant patterns are also attributed to the operation of exogenous environmental factors, e.g., underlying landscape heterogeneity, fire regimes or grazing regimes (Lovett et al., 2005). However, there is growing evidence that scale-free patterns can arise from endogenous, self-organising processes, including local-facilitation (e.g., Scanlon et al., 2007, Kéfi et al., 2007, von Hardenberg et al., 2010; Zhao et al., 2019). Our study suggests that eroded rangelands in Iceland are an example of a scale-invariant pattern, one that arises from endogenous, selforganising processes. 
The range of patch-sizes observed at our sites was large (up to seven orders of magnitude) across all levels of erosion cover. Furthermore patch size distributions at five sites had a PL distribution. Although not all the patch-size distributions could be reasonably characterised by power-laws, we suggest that erosion patches lack a characteristic scale, and the patch size distribution could be described as scale-invariant. The persistence of scale-invariant erosion patterns across a wide range of erosion covers (5-47\%) suggested that these patches did not form by chance. Our model results support this assertion. Null models at low levels of overall erosion cover showed a small range of patch sizes and CDF distributions that were far from a PL. The most likely explanation for the patterns of erosion observed is positive local-feedbacks in the biotic and abiotic dimensions of erosion and revegetation.

Most of the empirical examples of local-scale feedback proposed have focused on biotic positive feedbacks (e.g., the moderation of stressful microclimates by vegetation growth). In terms of erosion patches, the interaction of abiotic and biotic processes is likely to be important. In Iceland, erosion fronts often proceed laterally across the landscape (Arnalds, 2015) - sites adjacent to eroded areas are more likely to be eroded in the future. Plants near eroded areas will be under greater stress due to a decline in facilitation effects and reductions in soil moisture. There are also abiotic factors. In Iceland the boundaries between eroded and non-eroded areas are often defined by erosion escarpments (Icelandic: rofabard) (Arnalds, 2000). At these boundaries local-scale physical processes, particularly the erosion of sediment by wind and water, result in the lateral movement of erosion fronts across the landscape (Arnalds, 2000). Together, these processes provide a strong local-scale positive feedback for soil erosion, which is likely to be responsible for the generation of the distinctive erosion patterns we observed. This is supported by our erosion model which generated outputs with a large range of patch sizes and power-law type distributions (Table 3) qualitatively similar to our empirical datasets (Figure 8).

All our sites had more very large patches than would be expected under a PL distribution (Figure 4). However, our model outputs did not produce such large erosion patches. One explanation is that there is a difference in patch-persistence related to patch size. Large patches are more likely to persist and grow, whereas smaller patches may go through cycles of growth and collapse. Differences in patch persistence with erosion patch size were probably related to differences in surface cover of the area within patches. Large erosion patches are likely to be eroded down to underlying bedrock or glacial lag deposits; recolonization of these areas by plants is unlikely. In contrast, small erosion patches are characterised by exposed soil/sediment. Consequently, there is a chance that they will 'heal' (be recolonised by vegetation). As they become larger (and deeper) the sediment cover disappears, decreasing the likelihood of healing. The longer the erosion patch exists, the more likely it is to lose all its sediment, persist and grow larger. To test this, future modelling work should investigate a more sophisticated way of addressing patch persistence, perhaps 
by incorporating two states of eroded ground cover (bare substrate and exposed soil), with differing likelihoods of recolonisation.

In an influential paper, Kéfi et al (2007) argued that deviations from power-law patch size distributions may provide warnings for abrupt transitions and provide information about the ecological resilience of a site. These findings have been disputed (e.g., Maestre and Escudero, 2009). However, if they are applicable, they could provide an important metric for understanding landscape resilience. The main finding of Kéfi et al (2007) is that large vegetation patches fragment in stressed locations, leading to a truncation of the power-law relationship. When considering erosion patches, we might expect the opposite effect in stressed environments, i.e., an increasing over-abundance of very large patches with increased stress (hypothesis H2). However, we did not observe a consistent change in patchsize distribution along our environmental gradient: the persistence of large-patches and the fact that their size may be unrelated to contemporary environmental conditions suggests that deviations from a PL distribution in this environment are unlikely to provide meaningful information on site resilience. Our patch-size distribution results support the idea that there is no single scaling law of ecosystem structure (c.f. Maestre and Escudero, 2009), and highlight the importance of site-specific understandings of ecosystem functioning.

\subsection{Erosion-patch locations and mechanisms of patch growth}

We hypothesised that erosion patches would cluster in space (hypothesis H3). Our data supported this position. One explanation is that aggregation reflects underlying site heterogeneity. We know that relatively small changes in topography can affect plant growth, reproduction and survival, particularly when environmental conditions are stressful (Billings, 1987). Topographic variation on our sites was limited. Furthermore, the high level of erosion patch aggregation we observed, combined with our model results, suggested that the spatial pattern of the erosion patches is mainly a result of endogenous erosion feedbacks, especially localised disturbance processes. Small patches mostly occurred in clusters. However, isolated patches do exist, and may play an important role in the creation of large, stable erosion patches. In our model, small erosion patches had a small probability of forming, and were randomly distributed in space. In a random spatial process, some erosion events will naturally occur close to each other. This increases the local stress level, making it more likely that other patches will form nearby, and that existing patches will enlarge. If there are sufficient patches nearby, and if these patches persist, it is likely that they will coalesce. This observation is also supported by model results, which demonstrated how in times of increased global-scale stress, the enhanced generation of randomly placed erosion spots makes the initiation of more persistent and larger erosion spots more likely (Figure 9b). 
Our data also point to an additional mechanism which clusters patches together. Small erosion patches are much more likely to be found near to the edge of larger erosion patches. One explanation for this is a stress gradient that exists close to the boundaries of large patches. Increased stress close to the margins of large patches mean that small patches preferentially form in this zone, and once formed, are less likely to heal. These patches then grow, coalesce and extend the margins of the large patch that initiated their formation. The stress gradient may be related to moisture availability. Large patches are big (and old) enough to have eroded sediment down to bedrock, lowering the local water table and increasing moisture stress. Measurements of near-surface soil moisture we have made on another site in Iceland suggest moisture availability is reduced in a zone extending $\sim 1 \mathrm{~m}$ from the edge of an erosion patch (Figure S5). The redeposition of eroded sediment close to the erosion patch margin could also cause stress by burial and abrasion (Streeter and Dugmore, 2013). Both factors are likely to be short-range (not more than a few metres).

\section{Implications for the future of eroded landscapes in Iceland}

It is likely that temperature and grazing pressure are the main global-scale stressors found in our study area. Our observations suggest that erosion patch formation is sensitive to temperature, with more patches formed at higher altitude and further inland sites. However, we did not find that the total eroded area reflects current global-scale stress levels. If we wish to understand how these landscapes will respond to future environmental changes at the site level, we need a better understanding of the relative importance of local feedbacks and global-scale stressors.

Our finding that erosion patterns are predominately the result of distance-weighted feedbacks (i.e., disturbance takes place near to already disturbed sites, recovery more likely near existing vegetation), rather than density-independent global-scale site stressors has implications for the probable future trajectory of Icelandic soil erosion. By themselves, positive local feedbacks would tend to lead to one state predominating over the other. For instance, if erosion feedbacks are stronger than vegetation feedbacks, then sites will tend to become almost fully eroded over time. We observed this in our model: where the localfeedbacks were stronger than the site-level metrics, the model either stayed almost entirely vegetated, or becomes almost entirely eroded. Scanlon et al. (2007) found patch-size power-law relationships which were stable over a wide range of vegetation cover levels. They attributed this to the interaction of local effects and the global-scale impact of rainfall.

The importance of abiotic processes in the growth of erosion patches, and their relative insensitivity to global-scale environmental conditions once they are initiated, suggests that the eroded areas may well continue to expand, despite an amelioration in site level environmental stress. Large patches, once they reach a sufficient size, will continue to grow, more or less independent of external environmental conditions. We observed this 
phenomenon in our model results (Figure 9b): once erosion had become established to a certain level, it increased in area independent of the global-scale stress levels. This finding is supported by observations in Iceland that erosion has been difficult to stop or reverse, even when grazing has been completely removed (Barrio et al., 2018; Marteinsdóttir et al., 2017). It has been suggested that there is a threshold in the proportion of eroded land, beyond which erosion becomes very difficult to stop (Thorsson, 2008; Barrio et al., 2018). A tentative threshold level of $35 \%$ has been proposed, based on a single Icelandic site (Thorsson, 2008). Our model results suggest a somewhat lower threshold of $\sim 15 \%$, but further empirical data and modelling work is required to provide more robust estimates of the threshold level, and to understand its variability between sites. However, completely eroded sites are rare in northeastern Iceland, despite the fact that erosion was probably initiated centuries ago. This either suggests that 1 ) the area eroded increases extremely slowly or 2) sites are responsive at some level to global-scale site stressors. Our observations from aerial photographs suggest that landscape change is very slow in this area. Together, these findings suggest that there is an 'erosion debt', and the total area eroded will probably increase regardless of management, and a reduction in overall levels of landscape stress.

\section{Acknowledgements}

We would like to thank Jónína Sigríður Porláksdóttir of the Rif field station, Raufarhöfn for assistance with obtaining sheep population data for the area. Thanks to NSF grant 1202692 for support to RS. NC was supported by a grant from Churchill College, Cambridge. Thanks to Jim Woollet for advice and support. DEMs provided by the Polar Geospatial Center under NSF-OPP awards 1043681, 1559691, and 1542736. An earlier version of this manuscript was improved following the suggestions of two reviewers.

\section{Data availability}

Data available for download from the Dryad Digital Repository: http://doi:10.5061/dryad.z34tmpg8j 


\section{References}

Amundson, R., Berhe, A.A., Hopmans, J.W., Olson, C., Sztein, A.E. \& Sparks, D.L. (2015) Soil and human security in the 21st century. Science, 348(6235). DOI: 10.1126/science.1261071.

Arnalds, A. (2005) Approaches to landcare - a century of soil conservation in Iceland. Land Degradation and Development, 16: 113-125.

Arnalds, O. (2000) The Icelandic 'rofabard' soil erosion features. Earth Surface Processes and Landforms. 25(1): 17-28

Arnalds, O. (2015) Soils of Iceland. Springer, Dordrecht.

Arnalds, O. \& Barkarson, B.H. (2003) Soil erosion and land use policy in Iceland in relation to sheep grazing and government subsidies. Socio-economic Factors in Soil Erosion and Conservation 6(1): 105-113.

Badderley, A., Rubak, E., Turner, R. (2015) Spatial Point Patterns: Methodology and Applications with R. Chapman and Hall/CRC Press

Barrio, I. C., Hik, D. S., Thorsson, J., Svavarsdottir, K., Marteinsdóttir, B., \& Jónsdóttir, I. S. (2018). The sheep in wolf's clothing? Recognizing threats for land degradation in Iceland using state-andtransition models. Land Degradation \& Development, 29(6), 1714-1725.

http://doi.org/10.1002/ldr.2978

Bertness, M. D., \& Callaway, R. (1994). Positive interactions in communities. Trends in Ecology \& Evolution, 9(5), 191-193. http://doi.org/10.1016/0169-5347(94)90088-4

Billings, W.D. (1987) Constraints to plant growth, reproduction and establishment in Arctic environments. Arctic and Alpine Research, 19: 357-365.

Callaway, R. M., Brooker, R. W., Choler, P., Kikvidze, Z., Lortie, C. J., Michalet, R., et al. (2002). Positive interactions among alpine plants increase with stress. Nature, 417(6891), 844-848. http://doi.org/10.1038/nature00812

Clauset, A., Shalizi, C. R., \& Newman, M. E. J. (2009). Power-law distributions in empirical data. SIAM Review, 51(4), 661-703. http://doi.org/10.1137/070710111

Dale, M. R. T. (1999) Spatial Pattern Analysis in Plant Ecology. Cambridge University Press, Cambridge.

Dugmore, A. J., \& Erskine, C. C. (1994) Local and regional patterns of soil erosion in southern Iceland. Münchener Geographische Abhandlungen 12: 63-79. 
Dugmore, A.J., Gisladóttir, G., Simpson, I.A. \& Newton, A. (2009) Conceptual models of 1200 years of Icelandic soil erosion reconstructed using tephrochronology. Journal of the North Atlantic, 2: 1-18.

Fortin, M.J., \& Dale, M. (2005) Spatial analysis: a guide for ecologists. Cambridge University Press, Cambridge.

Grosse, G., Harden, J., Turetsky, M., McGuire, A.D., Camill, P., Tarnocai, C., Frolking, S., Schuur, E.A.G., Jorgenson, T., Marchenko, S., Romanovsky, V., Wickland, K.P., French, N., Waldrop, M., Bourgeau-Chavez, L., \& Striegl, R.G. (2011) Vulnerability of high-latitude soil organic carbon in North America to disturbance. Journal of Geophysical Research-Biogeosciences, 116. DOI: 10.1029/2010jg001507

Haase, P. (1995) Spatial pattern analysis in ecology based on Ripley's K-function: Introduction and methods of edge correction. Journal of Vegetation Science. 6(4): 575-582

Hardenberg von, J., Kletter, A.Y., Yizhaq, H., Nathan, J., \& Meron, E. (2010) Periodic versus scale-free patterns in dryland vegetation. Proceedings of the Royal Society B: Biological Sciences. 277(1688): 1771-1776: doi:10.1098/rspb.2009.2208.

Heindel, R. C., Chipman, J. W., \& Virginia, R. A. (2015). The Spatial Distribution and Ecological Impacts of Aeolian Soil Erosion in Kangerlussuaq, West Greenland. Annals of the Association of American Geographers, 105(5), 875-890. http://doi.org/10.1080/00045608.2015.1059176

Hilton, R.G., Galy, V., Gaillardet, J., Dellinger, M., Bryant, C., O'Regan, M., Grocke, D.R., Coxall, H., Bouchez, J. \& Calmels, D. (2015) Erosion of organic carbon in the Arctic as a geological carbon dioxide sink. Nature, 524(7563): 84-87.

IPCC (2013) Climate Change 2013: The Physical Science Basis. Cambridge University Press, Cambridge.

IPCC (2014) Climate Change 2014: Impacts, Adaptation, and Vulnerability. Cambridge University Press, Cambridge.

Kéfi, S., Rietkerk, M., Alados, C. L., Pueyo, Y., Papanastasis, V. P., ElAich, A., \& de Ruiter, P. C. (2007). Spatial vegetation patterns and imminent desertification in Mediterranean arid ecosystems. Nature, 449(7159), 213-217. http://doi.org/10.1038/nature06111

Kéfi, S., Guttal, V., Brock, W.A., Carpenter, S.R., Ellison, A.M., Livina, V.N., Seekell, D.A., Scheffer, M., van Nes, E.H. and Dakos, V. (2014). Early warning signals of ecological transitions: methods for spatial patterns. PLoS One, 9(3): 13.

Kristinsson, H. (2010) Flowering plants and ferns of Iceland. Mál og Menning: Reykjavik

Lal, R. (2014) Soil Carbon Management and Climate Change. In: A.E. Hartemink and K. McSweeney (Editors), Soil Carbon. Progress in Soil Science, pp. 339-361. 
Lovett, G. M., Jones, C. G., Turner, M. G. \& Weathers, K. C. (eds) (2005) Ecosystem function in heterogeneous landscapes. New York, NY: Springer.

Marteinsdóttir, B., Barrio, I. C., \& Jónsdóttir, I. S. (2017). Assessing the Ecological Impacts of Extensive Sheep Grazing in Iceland. Icelandic Agricultural Sciences, 30, 55-72.

http://doi.org/10.16886/IAS.2017.07

Maestre, F. T., \& Escudero, A. (2009). Is the patch size distribution of vegetation a suitable indicator of desertification processes? Ecology, 90(7), 1729-1735. http://doi.org/10.1890/08-2096.1

Meloni, F., Granzotti, C. R. F., Bautista, S., \& Martinez, A. S. (2017). Scale dependence and patch size distribution: clarifying patch patterns in Mediterranean drylands. Ecosphere, 8(2), e01690.

http://doi.org/10.1002/ecs2.1690

Moreno-de las Heras, M., Scaco, P. M., Willgose, G. R., \& Tongway, D. J. (2011). Assessing landscape structure and pattern fragmentation in semiarid ecosystems using patch-size distributions.

Ecological Applications, 21(7), 2793-2805.

Ólafsdóttir, R. and Guđmundsson, H.J. (2002) Holocene land degradation and climatic change in northeastern Iceland. Holocene, 12(2): 159-167.

Pettorelli, N., Vik, J.O., Mysterud, A., Gaillard, J-M., Tucker, C.J., \& Stenseth, N.C. (2005). Using the satellite-derived NDVI to assess ecological responses to environmental change. Trends in Ecology \& Evolution, 20(9), 503-510.

Porter, C., Morin, P., Howat, I., Noh, M-J., Bates, B., Peterman, K., Keesey, S., Schlenk, M., Gardiner, J., Tomko, K., Willis, M., Kelleher, C., Cloutier, M., Husby, E., Foga, S., Nakamura, H., Platson, M., Wethington, M. Jr., Williamson, C., Bauer, G., Enos, J., Arnold, G., Kramer, W., Becker, P., Doshi, A., D'Souza, C., Cummens, P., Laurier, F., Bojesen, M., 2018.

"ArcticDEM", https://doi.org/10.7910/DVN/OHHUKH, Harvard Dataverse, V1, [23 ${ }^{\text {rd }}$ August 2019].

Rietkerk, M., Dekker, S.C., de Ruiter, P.C., \& van de Koppel, J. (2004) Self-organized patchiness and catastrophic shifts in ecosystems. Science, 305(5692): 1926-1929.

Rietkerk, M., \& van de Koppel, J. (2008) Regular pattern formation in real ecosystems. Trends in ecology \& evolution 23(3): 169-175: doi:10.1016/j.tree.2007.10.013.

Scanlon, T. M., Caylor, K. K., Levin, S. A., \& Rodriguez-Iturbe, I. (2007). Positive feedbacks promote power-law clustering of Kalahari vegetation. Nature, 449(7159), 209-212. http://doi.org/10.1038/nature06060

Scheffer, M., Carpenter, S., Foley, J.A., Folke, C., \& Walker, B. (2001) Catastrophic shifts in ecosystems. Nature, 413(6856): 591-596. 
Schindelin, J., Arganda-Carreras, I., Frise, E., Kaynig, V., Longair, M., Pietzsch, T., et al. (2012). Fiji: an open-source platform for biological-image analysis. Nature Methods, 9(7), 676-682.

http://doi.org/10.1038/nmeth.2019

Stauffer, D., Adler, J., \& Aharony, A. (1994) Universality at the 3-dimensional percolation threshold. Journal of Physics a-Mathematical and General, 27(13): L475-L480.

Streeter, R., \& Dugmore, A. J. (2013) Anticipating land surface change. Proceedings of the National Academy of Sciences of the United States of America 110: 5779-5784.

Streeter, R., Dugmore, A. J., Lawson, I. T., Erlendsson, E., \& Edwards, K. J. (2015). The onset of the palaeoanthropocene in Iceland: Changes in complex natural systems. The Holocene, 25(10), 16621675. http://doi.org/10.1177/0959683615594468

Tape, K.D., Verbyla, D. \& Welker, J.M. (2011) Twentieth century erosion in Arctic Alaska foothills: The influence of shrubs, runoff, and permafrost. Journal of Geophysical Research. 116(G4): 1: doi:10.1029/2011JG001795.

Thorsson, J. (2008) Desertification of high latitude ecosystems: conceptual models, time-series analyses and experiments. PhD thesis, Texas A\&M University.

Veđurstofa Íslands, 2019. Climatological Data, Icelandic Meteorological Office. http://en. vedur.is/climatology/data/http://en.vedur.is/climatology/data/ (Accessed 29/09/ 2019).

Watt, A.S. (1947) Pattern and process in the plant community. Journal of Ecology, 35: 1-22.

Wilensky, U. 1999. NetLogo. http://ccl.northwestern.edu/netlogo/. Center for Connected Learning and Computer-Based Modeling, Northwestern University. Evanston, IL.

Zhao, L.-X., Xu, C., Ge, Z.-M., van de Koppel, J., \& Liu, Q.-X. (2019) The shaping role of selforganization: linking vegetation patterning, plant traits and ecosystem functioning. Proceedings of the Royal Society B, 286. DOI:10.1098/rspb.2018.2859.

\section{Supporting Information}

Additional text on the study site and model, and additional figures and tables are included in the supporting information. 


\section{Tables}

Table 1 - Characteristics of the study sites.

\begin{tabular}{|c|c|c|c|c|c|c|}
\hline $\begin{array}{l}\text { Site } \\
\text { Nam } \\
\text { e }\end{array}$ & $\begin{array}{l}\text { Latitude of } \\
\text { site centre }\end{array}$ & $\begin{array}{l}\text { Longitude of } \\
\text { site centre }\end{array}$ & $\begin{array}{l}\text { Elevation } \\
\text { (m asl) }\end{array}$ & $\begin{array}{l}\text { Distance from } \\
\text { coast }(\mathrm{km})\end{array}$ & $\begin{array}{l}\text { Proportion } \\
\text { Eroded }(\%)\end{array}$ & $\begin{array}{l}\text { Area } \\
\text { Surveyed } \\
\left(\mathrm{m}^{2}\right)\end{array}$ \\
\hline A & 66.21579 & -15.63137 & $11-20$ & 0.6 & 5.6 & 57600 \\
\hline B & 66.20333 & -15.64174 & $64-81$ & 2 & 22.8 & 62500 \\
\hline C & 66.17448 & -15.72192 & $61-75$ & 5.7 & 19.2 & 62500 \\
\hline D & 66.15898 & -15.75408 & $56-71$ & 7.1 & 47.3 & 62500 \\
\hline E & 66.1545 & -15.75761 & $67-79$ & 7.4 & 38.7 & 62500 \\
\hline F & 66.14428 & -15.7808 & $73-84$ & 9.8 & 25.0 & 62500 \\
\hline G & 66.13736 & -15.78105 & $85-106$ & 10.5 & 22.9 & 62500 \\
\hline H & 66.13242 & -15.79344 & $103-125$ & 11.2 & 14.9 & 62500 \\
\hline I & 66.12847 & -15.7999 & $130-154$ & 11.7 & 32.9 & 62500 \\
\hline J & 66.1127 & -15.76951 & $160-184$ & 12.9 & 26.2 & 62500 \\
\hline K & 66.10716 & -15.77083 & $192-208$ & 13.5 & 30.0 & 62500 \\
\hline L & 66.09961 & -15.77415 & $207-223$ & 14.3 & 24.0 & 62500 \\
\hline
\end{tabular}


Table 2. Summary of scaling parameters and statistics for PL models fitted to erosion patchsize CDFs. Statistically significant results indicated in bold. Positive likelihood ratio values indicate that the PL model is favoured over the LN model.

\begin{tabular}{|c|c|c|c|c|c|}
\hline & \multicolumn{3}{|c|}{ Power-law } & \multicolumn{2}{c|}{ Log-normal } \\
\hline Site & $\beta$ & $\mathrm{X}_{\min }$ & $p^{+}$ & Likelihood ratio & $p$ \\
\hline A & 2.27 & 1.50 & $\mathbf{0 . 5 1}$ & 0.11 & 0.91 \\
\hline B & 1.96 & 2.16 & $\mathbf{0 . 2 4}$ & 0.12 & 0.90 \\
\hline C & 1.82 & 0.08 & $\mathbf{0 . 0 7}$ & 0.41 & 0.68 \\
\hline D & 1.86 & 0.09 & $\mathbf{0 . 1 3}$ & 0.28 & 0.78 \\
\hline E & 1.84 & 0.07 & 0.01 & 0.49 & 0.62 \\
\hline F & 1.81 & 0.25 & 0.02 & 0.23 & 0.82 \\
\hline G & 2.01 & 0.13 & 0.00 & 0.44 & 0.66 \\
\hline H & 2.10 & 1.12 & $\mathbf{0 . 9 2}$ & 0.15 & 0.88 \\
\hline I & 2.01 & 1.01 & $\mathbf{0 . 7 8}$ & 0.15 & 0.88 \\
\hline J & 1.78 & 0.13 & 0.00 & 0.35 & 0.73 \\
\hline K & 1.93 & 0.13 & 0.00 & 0.37 & 0.71 \\
\hline L & 2.04 & 0.13 & 0.00 & 0.51 & 0.61 \\
\hline
\end{tabular}

+ Statistical significance for PL models is denoted when $p>0.05$ (see Clauset et al., 2009) 
Table 3 - Ability of the random null model and the erosion model to produce PL type distributions, based on 100 model runs.

\begin{tabular}{|c|c|c|c|c|c|c|c|c|}
\hline & \multicolumn{4}{|c|}{ Random null model } & \multicolumn{4}{c|}{ Erosion model } \\
\hline $\begin{array}{c}\text { Proportion } \\
\text { eroded }\end{array}$ & $\beta \leq 2$ & $p \geq 0.05$ & $\begin{array}{c}\text { Both } \\
\text { true }\end{array}$ & $\begin{array}{c}\text { Mean largest } \\
\text { patch size }\left(\mathrm{m}^{2}\right)\end{array}$ & $\beta \leq 2$ & $p \geq 0.05$ & $\begin{array}{c}\text { Both } \\
\text { true }\end{array}$ & $\begin{array}{c}\text { Mean largest } \\
\text { patch size }\left(\mathrm{m}^{2}\right)\end{array}$ \\
\hline 0.05 & 0 & 6 & 0 & 0.2 & 0 & 43 & 0 & 0.5 \\
\hline 0.15 & 0 & 40 & 0 & 0.8 & 80 & 59 & 39 & 18.9 \\
\hline 0.25 & 0 & 60 & 0 & 2.6 & 81 & 48 & 30 & 49.9 \\
\hline 0.35 & 35 & 40 & 1 & 21.2 & 85 & 62 & 47 & 104.7 \\
\hline 0.45 & 41 & 95 & 41 & 663.4 & 90 & 78 & 68 & 217.9 \\
\hline 0.55 & 87 & 71 & 71 & 873.7 & 94 & 78 & 72 & 450.9 \\
\hline
\end{tabular}




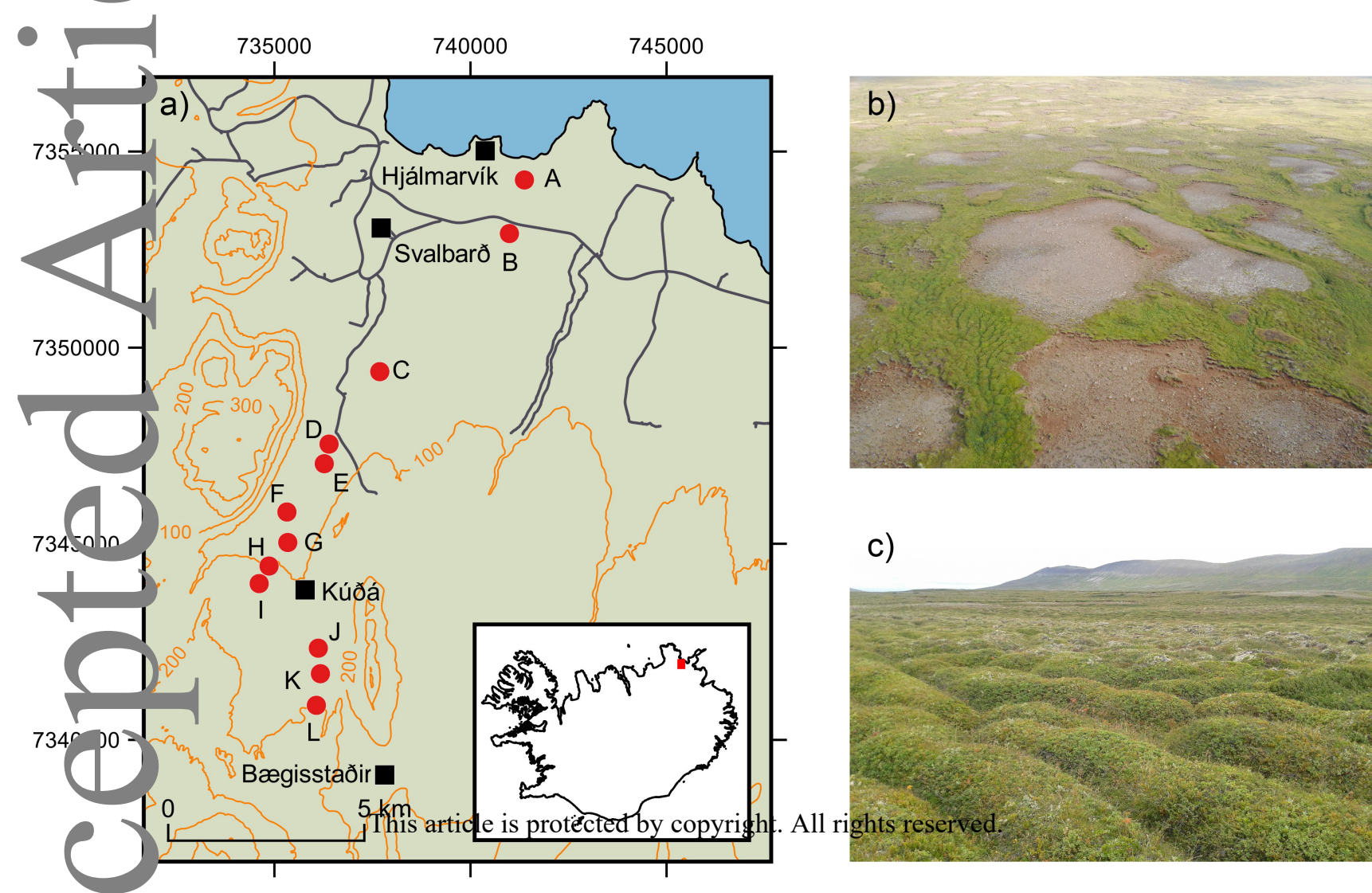




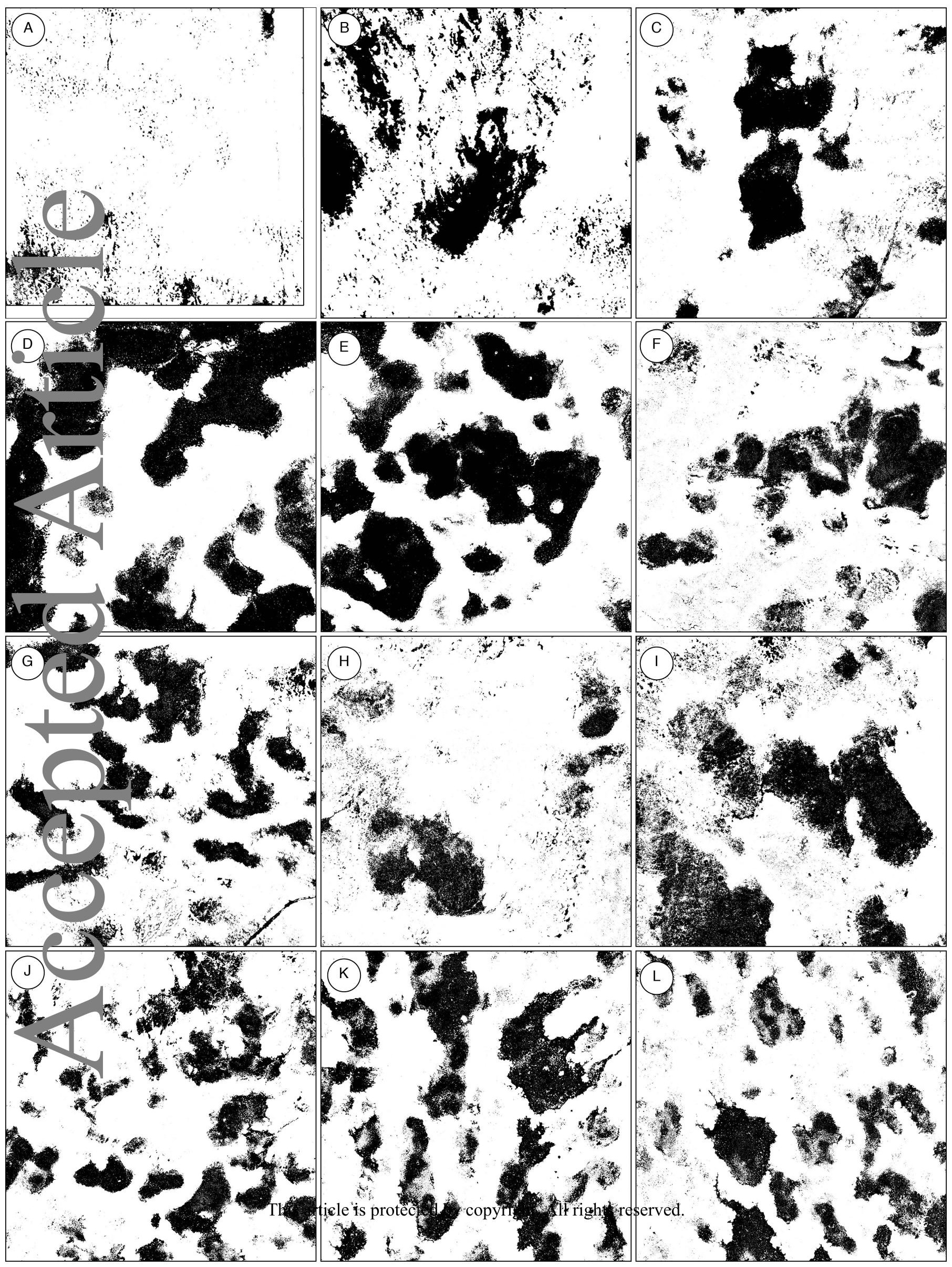




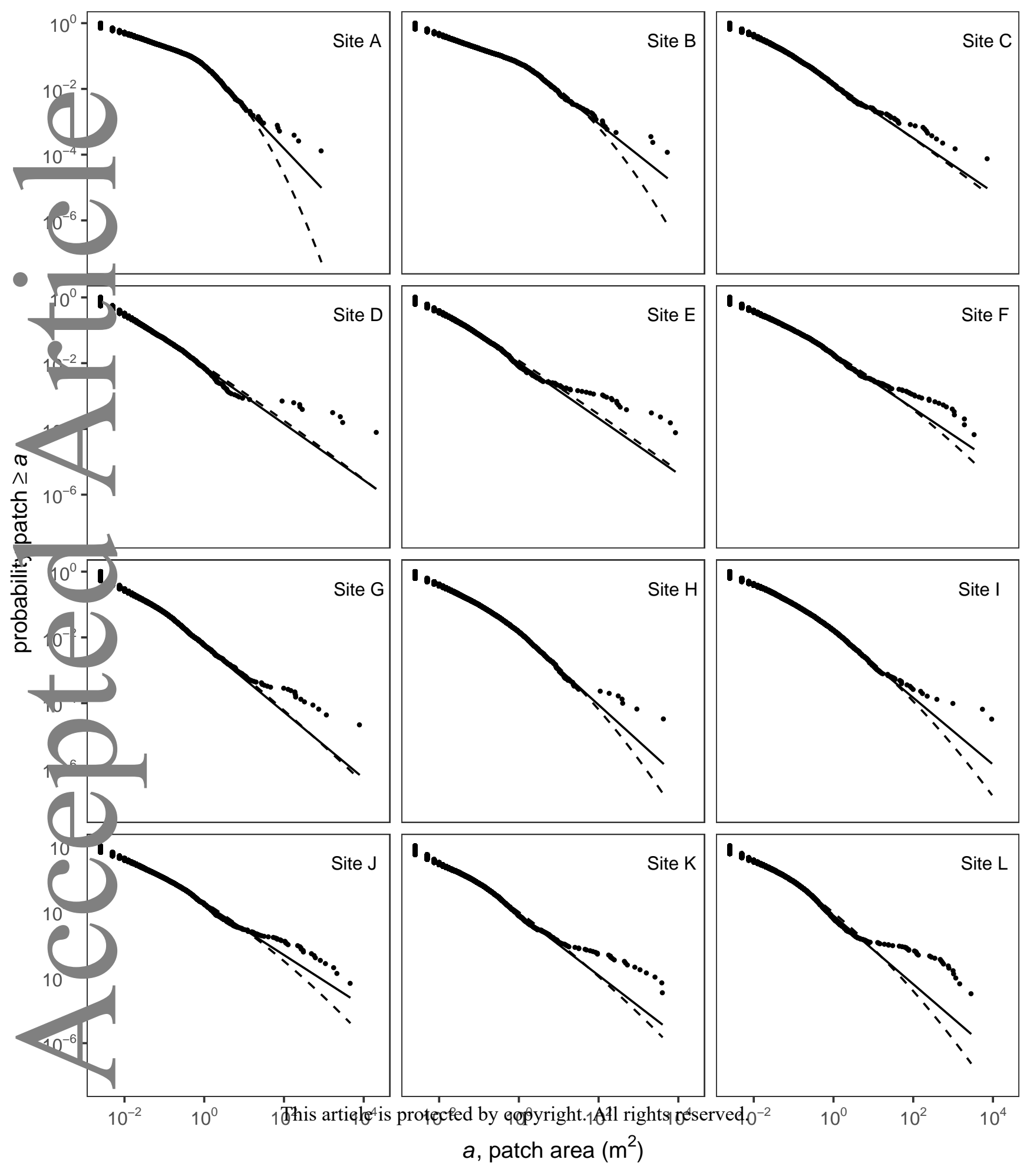




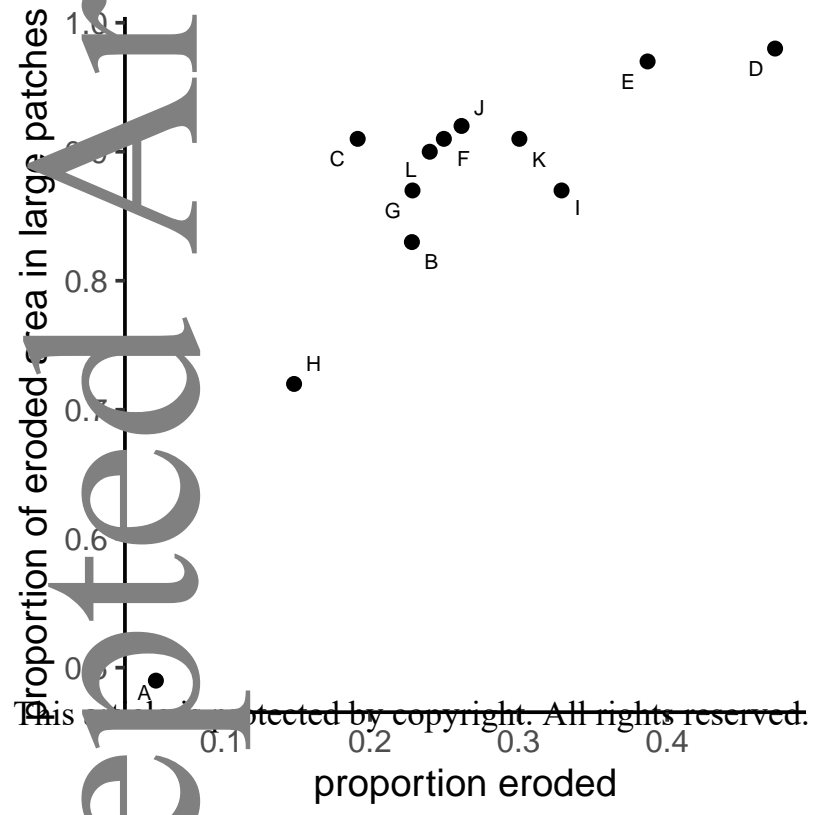


